\title{
The Implementation of the SDGs: The Feasibility of Using the GPEDC Monitoring Framework
}

\author{
Debapriya Bhattacharya, Victoria Gonsior, and Hannes Öhler
}

\subsection{INTRODUCTION}

Achieving the 2030 Agenda for Sustainable Development with its 17 Sustainable Development Goals (SDGs) requires significant behavioural changes on the global, regional, national, and sub-national levels from a variety of actors, including actors in development cooperation. Although significant progress was achieved in the era of the Millennium Development Goals-the predecessors of the SDGs-a wide variety of challenges remained; within the prevailing framework of the Millennium Development Goals, "development and sustainability aspirations were largely approached disjointly" (Kharas and Rogerson 2017, p. 18). Kharas and Rogerson (2017) list, for instance, the underdeveloped role of non-state and private actors, the inadequate concern for peace and institutions, and the strong emphasis on goals that were relatively easy to

D. Bhattacharya

Centre for Policy Dialogue (CPD), Dhaka, Bangladesh

e-mail: deb.bhattacharya@cpd.org.bd

V. Gonsior $(\bowtie)$

German Development Institute / Deutsches Institut für Entwicklungspolitik (DIE), Bonn, Germany

H. Öhler

German Development Institute / Deutsches Institut für Entwicklungspolitik (DIE), Bonn, Germany

e-mail: hannes.oehler@die-gdi.de

(C) The Author(s) 2021

S. Chaturvedi et al. (eds.), The Palgrave Handbook of Development

Cooperation for Achieving the 2030 Agenda,

https://doi.org/10.1007/978-3-030-57938-8_14 
measure. Today, the SDGs aim at addressing these shortcomings and introducing a narrative that is broader in scope and takes into account a diverse landscape of actors as well as development, in developing and developed countries alike (Fukuda-Parr 2017; Fukuda-Parr and McNeill 2019; The World in 2050 2018). In addition, the SDGs comprise-next to outcome targetstargets aiming at behavioural changes, such as targets addressing the means of implementation, SDG 17 (Partnerships for the goals), and targets focussing on processes and institutions (e.g. Engberg-Pedersen and Zwart 2018). These behavioural changes refer to a wide range of phenomena, including but not limited to empowering women, creating global partnerships, and building reliable and well-functioning institutions.

However-and as pointed out by the editors in the introduction of this book-as an implication of its broader nature, the SDGs do not address questions of responsibility and, subsequently, do not give guidelines or plans to review and follow up on the behavioural changes of specific actors. For example, the editors point out that SDG 17 is about promoting global partnerships, including public-private and civil society partnerships, but it does not provide concrete guidance for implementation. Arguably, the question of how to implement these envisaged behavioural changes in development cooperation is an important one for achieving the 2030 Agenda. This question is not covered by its follow-up and review (FUR) processes through a systematic approach. In fact, the United Nations (UN) does not have a global mechanism in place that steadily monitors the performance of all actors involved in development cooperation. According to Bexell and Jönsson (2017, p. 25), this might lead to unsystematic accountability and possibly encourage domestic political considerations and political will. ${ }^{1}$ Within this context, it is open to question whether the Global Partnership for Effective Development Cooperation (GPEDC) can, through its monitoring framework, fill the gap and, thus, provide a significant contribution to the implementation of the SDGs.

The GPEDC, established in Busan in 2011, is a multi-stakeholder platform that brings together all types of development actors. The purpose of the GPEDC is to improve the practices of development cooperation partners, their means of implementation, processes, and institutions. The GPEDC's flagship product is the monitoring framework. The monitoring framework, consisting of 10 indicators, aims at enhancing the effectiveness of development cooperation and ultimately achieving development impact. ${ }^{2}$ Following up on the effectiveness agenda agreed on in the Paris Declaration (2005) and the Accra Agenda for Action (2008), ${ }^{3}$ the monitoring framework focusses on four effectiveness principles, that is, ownership, results orientation, inclusive development partnerships, and transparency and accountability. In order to implement these principles, development partners ${ }^{4}$ and partner countries participating in the platform and its monitoring framework committed themselves to change the way they conduct development cooperation at the country level.

To answer the question whether the GPEDC, through its monitoring framework, can provide a significant contribution to the implementation of the SDGs, this chapter discusses critical political and technical factors that either 
positively or negatively influence the feasibility of such a contribution. The political factors strengthening the framework's potential contribution mainly comprise the complementarity of the GPEDC monitoring framework to the SDGs. On the contrary, the limited enthusiasm of development partners from the Global South, in particular China and India, as well as the limited amount of attention being paid by member countries of the Organisation for Economic Co-operation and Development (OECD) to the platform and the monitoring framework, can be seen as major political factors inhibiting a potential contribution.

Important technical factors benefitting a potential contribution are the significant share of behavioural changes envisaged by the SDGs that are applied by the monitoring framework to development cooperation and the large volume of empirical data that is generated biennially through the monitoring rounds. However, the empirical data is not being used as productively as it could be because interpretive evaluations of all stakeholders, especially of the performance of development partners, are largely missing. Hence, follow-up processes, most importantly at the national level, are limited. We conclude that making effective use of and developing the positive factors further, while taking into account and addressing, if possible, the negative factors, could lead to a significant contribution of the GPEDC, through its monitoring framework, to the implementation of the SDGs. We also discuss potential strategies in this regard.

This chapter is structured as follows: Sect. 14.2 embeds the GPEDC in a broader series of political events and presents the monitoring framework itself. In Sect. 14.3, we present critical political as well as technical factors that either positively or negatively influence the feasibility of a significant contribution to the implementation of the SDGs on the part of the GPEDC monitoring framework. In the last section, we discuss potential strategies to make effective use of positive factors and address negative ones.

\subsection{The GPEDC Monitoring Framework ${ }^{5}$}

\subsubsection{Context: Emergence, Evolution, and Current Structure}

The establishment of the GPEDC, in 2011 in Busan, is embedded in a broader series of political events, which all centre on the issue of how to enhance the impact of development cooperation (Abdel-Malek 2015). The GPEDC's origins may be traced back to the UN Financing for Development Conference held in Monterrey in 2002. Between 2002 and 2011, three High Level Fora on Aid Effectiveness—held in Rome (2003), Paris (2005), and Accra (2008) provided a platform for international dialogue on the aid effectiveness agenda, which reached its climax with the adoption of the Paris Declaration in 2005.

Thereafter, at the High Level Forum in Busan in 2011, policy-makers discussed intensively the results of the "2011 Survey on Monitoring the Paris Declaration" and reviewed the progress made. ${ }^{6}$ The outcome document 
postulated the establishment of the multi-stakeholder platform the GPEDC. The GPEDC aims at monitoring the implementation of effectiveness principles, which should mirror development effectiveness, rather than the narrower concept of aid effectiveness. Development effectiveness thereby refers to the overall achievement of development results and acknowledges a variety of actors in, and means for, achieving those (Kim 2013).

The post-Busan dialogue was carried forward in two high-level meetings (HLMs) that took place in Mexico City (2014) and Nairobi (2016). ${ }^{7}$ These HLMs gave rise to a series of agreements that increasingly urged development partners to focus on nationally determined priorities and, at the same time, urged partner countries to take stronger leadership roles to guide development partners' efforts and facilitate approaches to development (Lundsgaarde and Keijzer 2016).

In 2011, the GPEDC was endorsed by 161 countries and 56 organisations. The GPEDC is led by a Steering Committee, which currently has 25 members, including representatives of development partners, partner countries, the multilateral system, the private sector, as well as public representatives and representatives from civil society. The Steering Committee has three CoChairs-a member country of the OECD, a development cooperation partner country, and a development partner of South-South cooperation (SSC). Most recently, a non-executive $\mathrm{Co}$-Chair was appointed representing nongovernmental stakeholders (e.g. non-governmental organisations (NGOs) and civil society organisations, private philanthropies, parliamentarians, the private sector, and trade unions). A Joint Support Team (JST) located at the OECD in Paris and the United Nations Development Programme (UNDP) in New York provides technical and administrative backup for the GPEDC.

\subsubsection{The Monitoring Exercise and Its Underlying Framework}

The GPEDC's flagship product, the global framework, monitors the implementation of four effectiveness principles: ownership, results orientation, inclusive development partnerships, and transparency and accountability. The monitoring takes place every two years $(2014,2016$, and 2018 , so far); the number of partner countries participating in the exercise rose in 2018 to 87 countries, which amounts to six more participating partner countries than in the previous round (2016) (Global Partnership for Effective Development Co-operation [GPEDC] 2019a). The monitoring focusses on official development assistance (ODA). However, in order to provide a more comprehensive picture of the development resources flowing into a partner country, development partners are encouraged to also report on other official flows, such as non-concessional loans.

The monitoring framework is based on 10 indicators that link to the four effectiveness principles (see Table 14.1). The monitoring framework adopted some of the indicators from the Paris and Accra agreements: results orientation [indicator 1], annual and medium-term predictability [indicator 5], on-budget 
Table 14.1 GPEDC monitoring framework-effectiveness principles and indicators

Focus on results

Ownership of development priorities by developing countries

Inclusive development partnerships

Transparency and accountability to each other
Development efforts must have Indicator: Countries a lasting impact on eradicating strengthen their national poverty and reducing inequality results frameworks (1b) and on enhancing developing Indicator: Development countries' capacities so that partners use country-led they are in alignment with results frameworks (la) their own priorities.

Partnerships for development Indicator: Development can only succeed if they are led cooperation is predictable: by developing countries that are implementing approaches, which are tailored to country-specific situations and needs. annual predictability (5a) Indicator: Development cooperation is predicatable: medium-term predicatability (5b)

Indicator: Quality of countries' public financial management systems (9a)

Indicator: Development partners' use of country systems $(9 b)$

Indicator: Aid is untied (10)

Openness, trust, mutual Indicator: Quality of public-private dialogue (3) respect, and learning lie at the core of effective partnerships, which recognise the different and complementary roles of all actors.

Indicator: Civil society organisations operate within an environment that maximises their engagement in and contribution to development (2)

Mutual accountability and accountability to the intended beneficiaries of development cooperation, as well as to respective citizens, organisations, constituents, and shareholders, is critical to delivering results. Transparent practices form the basis for enhanced accountability.
Indicator: Transparent information on development cooperation is publicly available (4) Indicator: Mutual accountability among development actors is strengthened through inclusive reviews (7) Indicator: Development cooperation is included in budgets subject to parliamentary oversight (6) Indicator: Countries have systems to track and make public allocations for gender equality and women's empowerment (8)

Source Authors' own graphical representation of the illustration in GPEDC (2018, p. 8) 
development cooperation [indicator 6], mutual accountability [indicator 7], quality and use of the partner countries' systems [indicator 9], and delivery of untied aid [indicator 10]. Other indicators were newly introduced in 2012 to reflect the broader dimensions of development effectiveness. These include indicator 2 (focussing on civil society), indicator 3 (covering publicprivate dialogue), indicator 8 (targeting gender equality), and lastly indicator 4 (aiming at transparency). Each indicator is comprised of a subset of questions and measures that ultimately aim at providing evidence on the progress of the implementation of the effectiveness principles.

Throughout the past years, the GPEDC monitoring framework has undergone an extensive review process. In 2015, the GPEDC Co-Chairs and Steering Committee mandated the Monitoring Advisory Group, a body of 12 experts, to review, refine, and advise on the continued relevance of the Global Partnership's "Theory of Change", as well as on the 10 indicators of its global monitoring framework (Monitoring Advisory Group 2016). The revised framework, including updated guidelines and indicators, found traction within the latest GPEDC monitoring round in 2018.

Importantly, the responsibility for the monitoring exercise at the country level lies with the partner countries. Each partner country that chooses to participate designates a national coordinator, who coordinates the monitoring exercise among all relevant actors, including the data collection process. The national coordinator collates, validates, and passes the data on to the OECD/UNDP Joint Support Team of the GPEDC for consistency and completeness checks and aggregation. As such, participation in the monitoring exercise requires extensive investments, especially in terms of the partner countries' resources in the form of available time and staff capacities.

\subsection{CONTRibuting to THE IMPLEMENTATION of the SDGs: Political and Technical Feasibility}

To achieve the 2030 Agenda, behavioural changes from a variety of stakeholders on the global, regional, national, and sub-national levels are required. In this regard, the GPEDC, through its monitoring framework, can potentially provide a significant contribution to the implementation of the SDGs in the context of development cooperation. This section discusses critical political and technical factors that influence the feasibility of such a contribution.

\subsubsection{Political Factors Influencing the Feasibility of a Significant Contribution of the Monitoring Framework to the Implementation of the SDGs}

In recent years, the relevance and political interest in the effectiveness agenda have largely vanished (Abdel-Malek 2015; Mawdsley et al. 2018). According to Koch et al. (2017) and Booth (2012), the main reason for the agenda's lack of success was its sophisticated technocratic character, which failed to 
address the political economy in which development cooperation is embedded. Hence, when assessing the feasibility of a significant contribution of the monitoring framework to the implementation of the SDGs, it is crucial to assess not only technical aspects, in terms of the indicators, for instance. Instead, political factors that shape the context in which the framework operates and that could ultimately prevent the aforementioned contribution from materialising also need to be taken into account.

\subsubsection{Factors Positively Influencing the Feasibility}

Primarily, the complementarity and alignment of the monitoring framework to the principles and objectives of the 2030 Agenda positively influences the feasibility of a significant contribution of the monitoring framework to the implementation of the SDGs. The 2030 Agenda does not mention the GPEDC explicitly. Nevertheless, when comparing the 2030 Agenda and the effectiveness principles of the GPEDC, it becomes apparent that the 2030 Agenda very much reflects the understanding of the GPEDC. For instance, part of paragraph 60 under "Means of Implementation and the Global Partnership" reads as follows:

We recognise that we will not be able to achieve our ambitious Goals and targets without a revitalised and enhanced Global Partnership and comparably ambitious means of implementation. The revitalised Global Partnership will facilitate an intensive global engagement in support of implementation of all the Goals and targets, bringing together governments, civil society, the private sector, the United Nations system and other actors and mobilising all available resources. (UN 2015, p. 28)

Although the term "Global Partnership" cannot directly be equated with the global partnership entailed in the name of the GPEDC-as it is a term coined during the United Nations Millennium Summit in 2000-a link to the GPEDC and how it envisions its contribution can be drawn through the notion of bringing multiple actors to the table. More specifically, the GPEDC presents its complementarity and alignment to the 2030 Agenda through its inclusion of emerging economies, the private sector, and civil society organisations, as well as through the creation of a multi-stakeholder platform (Coppard and Culey 2015). Furthermore, and in line with paragraph 63 of the 2030 Agenda, which emphasises the need for "cohesive nationallyowned sustainable development strategies, supported by integrated national financing frameworks" (United Nations [UN] 2015, p. 28), the GPEDC aims at increasing dialogue and encouraging the embedment of the principles of development effectiveness at various levels, including the national level. Only by doing so can its potential to provide a significant contribution to the implementation of the SDGs be "capitalised" (Coppard and Culey 2015, p. 3). 
Importantly, the adoption of the SDGs calls for significant behavioural changes on the global, regional, national, and sub-national levels of a variety of actors, including actors in development cooperation. In particular, next to outcome targets, the SDGs comprise targets aiming at behavioural changes. However, as an implication of its broader nature, the 2030 Agenda does not give guidelines or plans to review and follow up on behavioural changes of specific development actors. Arguably, the question of how to implement these behavioural changes in development cooperation is an important one for the 2030 Agenda and its FUR processes.

The Global Accountability Surveys of the UN Development Cooperation Forum on progress in national mutual accountability and transparencycarried out biennially since 2008 by the UN Department of Economic and Social Affairs-are designed to incentivise behavioural changes and provide evidence on how development cooperation is conducted at the country level. These surveys are centred around the assessment of mutual accountability, thereby aiming at supporting government efforts to strengthen development partnerships at the country level. ${ }^{8}$ However, these surveys mainly focus on the performance of government ministries and significantly less on development partners, calling into question whether the latter are held accountable in the context of the UN's own development cooperation monitoring and review mechanisms (United Nations Economic and Social Council 2018).

Within this context, the GPEDC monitoring framework can be seen as a valuable asset that could contribute to the monitoring of the SDGs. In fact, the monitoring framework is well-suited to facilitate behavioural changes in development cooperation and contribute to the monitoring framework of the SDGs, especially around the targets set under SDG 17. This could even be extended to the means of implementation for the targets of other goals (Coppard and Culey 2015).

Furthermore, the GPEDC seeks to instil mutual accountability among all actors engaged in development cooperation. With the inclusion of a wide range of actors in development cooperation-that is, governments of partner countries and development partner countries, multilateral organisations, civil society, the private sector, as well as other state and non-state actors-mutual accountability is created, even in the absence of an enforcement mechanism (Abdel-Malek 2015). ${ }^{9}$ Information on the actors' performance with regard to the 10 indicators is publicly accessible, thereby exercising peer pressure on the actors involved. Given that mutual accountability is crucial for the implementation of the SDGs, the exploitation of synergies and complementarities between the established GPEDC accountability framework and the accountability concept envisaged for the 2030 Agenda would be beneficial (Mahn 2017).

These factors point in the direction that the GPEDC and its monitoring framework is well-positioned to make a significant contribution to the implementation of the SDGs (Constantine et al. 2015). From a strategic point of 
view, harnessing these beneficial factors could lead to an increase in the relevancy of the monitoring framework and the GPEDC itself and may even lead to a revivification of the effectiveness agenda in development cooperation.

\subsubsection{Factors Negatively Influencing the Feasibility}

However, not all political factors strengthen the feasibility of the framework's contribution to the implementation of the SDGs. One political factor that reduces its feasibility is the monitoring framework's limitations in covering the overall development cooperation landscape as well as in taking recent changes into account. Already before the establishment of the GPEDC and the development of the monitoring framework, the development cooperation landscape had begun to change significantly (Bhattacharya and Khan 2018b). The emerging landscape is, among other aspects, characterised by the rise of important new actors from the Global South, especially China and India (e.g. Organisation for Economic Co-operation and Development [OECD] 2018b). These countries are increasingly taking on a dual role in development cooperation and enhancing their contributions with regard to concessional financial flows to other developing countries.

The failure of the GPEDC to also include contributions of SSC development partners in its monitoring framework stems from the lack of enthusiasm among these emerging economies. In fact, from the perspective of the Global South, the GPEDC monitoring framework is largely an OECD Development Assistance Committee (DAC) driven exercise with very limited reflection on SSC approaches and the SSC paradigm (Abdel-Malek 2015; Li 2017).

Furthermore, limited consideration of the private sector, transnational NGOs, and private philanthropies in the monitoring framework have fuelled the perception that the framework does not measure the effectiveness of the overall international development cooperation landscape. This is especially the case because these actors are increasingly providing large volumes of development finance to partner countries. A thorough reflection on the effectiveness of the contributions of these actors is missing, with the acknowledgement that reflecting on such a diverse actor landscape with manifold interests is highly challenging (e.g. Wehrmann [2018] who discusses challenges of including private-sector actors in effective sustainable development initiatives, with a particular focus on the GPEDC).

Another political factor limiting the feasibility of the framework's contribution to the implementation of the SDGs lies in the fact that not only emerging economies but also OECD-DAC members do not seem to be particularly enthusiastic about the monitoring framework itself, and the GPEDC multistakeholder platform in general. Given the voluntary nature of the original commitments, traditional development partners have often shied away from the exercise and demonstrated a lack of consequential attention to the results. In particular, political challenges at headquarters are largely responsible for the lack of progress in those areas where development partners' efforts were 
most required (see Koch et al. [2017] for a discussion on the reasons why the backing for budget support has largely vanished in the last decade). Changing domestic politics have further contributed to the lack of progress. Throughout the past years, the emergence of the migration narrative, the rise of nationalism and populism, and a new demand to include "national interests" transparently on the development policy agendas of OECD countries have been at the centre of attention in traditional donor countries (Barder 2018; Hulme 2016; Keijzer et al. 2018; Mawdsley et al. 2018). In addition, the nonparticipation in the monitoring exercise by new key development actors from the South, such as China and India, has relaxed the pressure on the traditional development partners to stick to their commitments.

This factor is further intensified by the observation that the GPEDC monitoring framework does not address the funding commitments made by development partner countries at various international fora. In particular, achieving the targets of allocating 0.7 per cent ODA/GNI (gross national income) to developing countries, or 0.15 to 0.20 per cent of ODA/GNI to least-developed countries is not a subject of the monitoring framework. However, one could argue that the monitoring of international ODA commitments by development partners does not really fit into the monitoring exercise of the GPEDC, which is an exercise led by partner countries on how development cooperation is conducted at the country level. A more suitable platform for monitoring these commitments would be arguably the UN Financing for Development Conference. ${ }^{10}$

\subsubsection{Technical Factors Influencing the Feasibility of a Significant Contribution of the Monitoring Framework to the Implementation of the SDGs}

Besides political factors, there are also a number of technical factors that either positively or negatively influence the monitoring framework's feasibility of contributing to the implementation of the SDGs.

\subsubsection{Factors Positively Influencing the Feasibility}

From a technical point of view, the question arises as to what extent the GPEDC monitoring framework, in its present form, is designed to keep track of the behavioural changes in development cooperation that are envisaged by the SDGs. The SDGs, while encompassing a large number of outcome-related goals and targets, also include a number of targets related to behavioural changes, which are mostly also relevant for actors in development cooperation at the country level-the level of interest for the monitoring framework. ${ }^{11}$ A detailed analysis shows that the monitoring framework with its 10 indicators fully applies to a significant number of SDG targets aiming at behavioural changes in development cooperation. ${ }^{12}$ Thus, the monitoring framework is generally well set up to promote the behavioural changes envisaged by the 
SDGs in development cooperation. Nevertheless, we also identify a number of targets that are only partly adopted by the monitoring framework, leaving some room for improvement. ${ }^{13}$

Another technical factor that could potentially enhance the framework's contribution to the SDGs is the fact that the monitoring framework regularly generates a large volume of empirical data on the country level on a global scale. Keeping track of these behavioural changes is crucial in the course of the implementation of the SDGs. In this regard, the monitoring framework generates data on a regular basis and in this way provides a large volume of empirical data on a global scale. The implementation of biennial monitoring rounds encourages development partners to follow a common methodology and standards for measuring development effectiveness, to disclose information about their development cooperation, and to smoothen the data collection process. The collected empirical data is ideally used to inform evidence-based decisionmaking at the global and local levels, and it enhances the pursuit of policy coherence for sustainable development in partner countries. Other attempts to address development effectiveness on a similar scale do not exist. Only a few alternative frameworks for the assessment of the quality of the contributions of development partners-such as the quality of ODA, which also relies to some extent on the GPEDC monitoring data, or the Commitment to Development Index — can be found. ${ }^{14}$

\subsubsection{Factors Negatively Influencing the Feasibility}

An aspect diminishing the feasibility of a significant contribution of the monitoring framework to the implementation of the SDGs is the lack of interpretive evaluations for all actors of the results of the respective monitoring rounds. Currently, the GPEDC monitoring framework collects data at the country level biennially and presents the aggregated data through a dashboard on their homepage. ${ }^{15}$ Additionally, the JST provides a global report and short country briefs for participating partner countries. ${ }^{16}$ However, the framework lacks an analysis of the results on the performance of development partners, including multilateral organisations, which are significantly contributing to the data collection exercise.

In addition, not only is the evaluation of the monitoring data limited, the monitoring framework also lacks respective feedback loops at the global and country levels to follow up on the rather extensive data collection process, inform stakeholders about the outcomes, and facilitate subsequently decision-making processes. As a result, no meaningful dialogue on followup commitments-bearing in mind the monitoring exercise's non-binding nature-is taking place, and the framework is proving to be insufficient at being able to profoundly inform and steer political debates on development effectiveness (Abdel-Malek 2015; Besharati 2013). Taken together, the last two aspects diminish the benefits of the monitoring exercise: especially at the 
country level, the results of the monitoring exercise are not being used as productively as they could be.

Not only from a political but also from a technical perspective, the framework's limitation in measuring the effectiveness of the overall changing development cooperation landscape is a factor that may hinder the feasibility of a significant contribution of the monitoring framework to the implementation of the SDGs. More specifically, the emerging SSC regime has been giving rise to a set of framework issues emerging from the fact that SSC is essentially different from traditional North-South and even trilateral cooperation relationships. These framework issues include, for example, monitoring indicators that do not sufficiently represent the evolution of thoughts within the SSC paradigm. At the same time though, a consensus regarding the need to assess the effectiveness of SSC is gradually emerging among the directly concerned stakeholders. Furthermore, discussions regarding distinguishing features of an assessment framework of South-South concessional flows are gathering momentum (Bhattacharya and Rashmin 2016).

Similar to the political and technical overlaps related to the SSC paradigm and traditional North-South development cooperation, a number of technical issues exist with regard to considerations about the contributions of the private sector, transnational NGOs, and private philanthropies in the monitoring exercise. In this regard, some emerging instruments in development cooperation, in particular blended finance (e.g. Attridge and Engen 2019; OECD 2018a), are trying to utilise the potential catalytic effect of ODA for mobilising additional resources, thereby involving a number of actors, especially from the private sector. ${ }^{17}$ However, at the moment there is no GPEDC indicator that reflects the effectiveness of the catalytic potential of ODA. Finally, financial sources beyond ODA, such as non-concessional spending, are also not being assessed against the principles of ownership, results orientation, inclusive development partnerships, as well as transparency and accountability.

\subsection{Discussion ANd Conclusion}

To answer the question of whether the GPEDC, through its monitoring framework, can provide a significant contribution to the implementation of the SDGs, this chapter has discussed critical political and technical factors that either positively or negatively influence the feasibility of such a contribution. The political factors having a positive influence mainly comprise the complementarity of the GPEDC monitoring framework to the SDGs. On the other hand, the limited enthusiasm and participation by development partners from the Global South, in particular China and India, as well as the limited amount of attention being paid by member countries of the OECD to the platform and monitoring exercise, can be seen as major political factors that reduce the potential contribution of the monitoring framework. Important technical factors benefiting such a contribution can be identified in the significant share of behavioural changes envisaged by the SDGs that are applied 
by the monitoring framework to development cooperation and the large volume of empirical data that is generated with the monitoring rounds biennially. However, the generated data is not being used as productively as it could be because interpretive evaluations of all stakeholders, especially of the performance of development partners, are largely missing, thereby limiting the monitoring framework's potential contribution.

Drawing on these findings, we conclude this chapter by deriving potential strategies for "updating" the institutional setting of the GPEDC by making effective use of the factors that foster a significant contribution of the monitoring framework to the implementation of the SDGs. However, we also stress that the GPEDC needs to address the factors that negatively influence its contribution in order to minimise their effects.

With respect to the complementarity of the GPEDC monitoring framework to the SDGs, Bhattacharya et al. (2016) argue that the 2030 Agenda presents a unique opportunity for the GPEDC monitoring framework to reinvent itself by substantially contributing to the FUR process of the SDGs. The GPEDC itself identifies its contribution through the monitoring framework through two potential options. On the one hand, the GPEDC monitoring framework could be merged into the SDG monitoring framework. On the other hand, the GPEDC could provide a complementary approach that would address the quality of inputs for monitoring the implementation of the SDGs in a broad sense (Coppard and Culey 2015).

As discussed in this chapter, the GPEDC monitoring framework is currently one of the few global mechanisms available that seeks to instil mutual accountability in development cooperation processes. In addition, the framework is well-suited to facilitate behavioural changes, as its monitoring indicators mostly focus on processes and means of implementation. Hence, it would be favourable if the FUR process of the SDGs built on these existing mechanisms to further promote mutual accountability and behavioural changes among actors in development cooperation.

However, the voluntary national reviews (VNRs) of 2016 and 2017 show that neither the VNRs in OECD countries nor in developing countries extensively mention the results of the GPEDC monitoring framework. Consequently, the question of how to ensure better and broader use of GPEDC monitoring in the FUR process needs to be assessed. The most straightforward solution is that when VNRs are prepared, the governments of participating partner countries can use the GPEDC's country profiles, which include the country-specific results of the respective last monitoring rounds. ${ }^{18}$ Moreover, these countries may utilise the findings of the monitoring exercise while drawing up their respective national SDG Action Plans. This would also provide the opportunity to subject the GPEDC output documents to scrutiny by a wider range of stakeholders and to improve the GPEDC monitoring framework further. In addition, it could stimulate important-currently missing - feedback loops of the results of the monitoring exercise. 
Similarly, the UN Department of Economic and Social Affairs can also be sensitised regarding the use of the JST's global report when preparing the annual SDG Progress Report, particularly when reporting on SDG 17. In fact, the results of the GPEDC monitoring were not used in the 2018 SDG Progress Report (UN 2018). Importantly, the GPEDC has to open up to the High-Level Political Forum on Sustainable Development and make its monitoring report available as one of the resource documents. From a medium- to long-term perspective, the GPEDC HLMs may be included within the workflow of the High-Level Political Forum on Sustainable Development. This may lead to greater levels of acceptance of the GPEDC platform and its monitoring framework in the global development community-in particular among SSC development partners-as a global mechanism to promote development effectiveness and the implementation of the SDGs.

However, in order for the previously mentioned developments to materialise, the GPEDC needs to address the limited levels of enthusiasm among SSC development partners by opening up to the SSC paradigm and considering the demands and needs of SSC development partners in the context of an envisaged monitoring framework that covers the overall development cooperation landscape. For instance, the SSC development partners argue in favour of including a wide range of non-concessional finance and activities in the framework, as this would imply that the framework comprises certain key aspects of their development cooperation, that is, mutual economic benefits and development knowledge from their own experiences (Constantine et al. 2015). In addition, Southern scholars have produced a large body of interesting work on the assessment framework of SSC (Besharati et al. 2017). These resources may work as reference points for reflections on the GPEDC monitoring framework. Furthermore, open-ended, evidence-based discussions followed up by a couple of pilot projects may be able to break new ground in improving mutual understanding between Southern and OECD development partners. Simultaneously though, in order to overcome the weakness of data comparability with OECD development partners, Southern development partners would need to create comprehensive and real-time data on their development projects. The GPEDC is currently experimenting with a pilot framework on SSC whereby the consideration of both aspects is taken on board (GPEDC 2019b).

In addition, the non-consideration of financial contributions from the private sector, philanthropies, and NGOs appears to be a drawback in the current design of the monitoring framework. Lastly, the GPEDC monitoring framework in particular, and the GPEDC multi-stakeholder platform in general, would need to be revitalised through the infusion of political enthusiasm, in particular among OECD member countries. One promising path could be the addition of interpretive evaluations of monitoring results and feedback loops to inform evidence-based, multi-stakeholder dialogues and increase the monitoring exercise's added value. 
The strategies present ideas for making effective use of the positive factors and diminishing the effects of the negative ones. Such efforts could increase the relevance of the monitoring framework, the GPEDC in general, and revive the effectiveness agenda on a global, regional, and local level.

\section{Notes}

1. For further discussion on SDG accountability, refer next to Bexell and Jönsson (2017) and to Bowen et al. (2017).

2. Note that no rigorous quantitative analysis has been conducted attesting the assumption that effective practices of development partners lead to development impact. Rather, advocacy for compliance with the effectiveness principles is based on theoretical arguments and anecdotal and qualitative evidence (Knack 2012). Anecdotal evidence is provided, for instance, by the World Bank (2003). Leiderer (2015) offers a more in-depth descriptive study on health and education outcomes in Zambia. A qualitative evaluation by Wood et al. (2011) finds that the implementation of the Paris Declaration principles has contributed to better development results in the health sector in most of the 21 recipient countries taking part in the evaluation.

3. For further information, refer to the Paris Declaration on Aid Effectiveness and the Accra Agenda for Action: https://www.oecd.org/dac/effectiveness/ 34428351.pdf.

4. With development partners, we refer to the group of actors providing financial (and potentially non-financial) resources to partner countries.

5 . The information presented in this section is based on key documents provided by the GPEDC itself, such as GPEDC/UNDP (2016) and GPEDC (2017), as well as Abdel-Malek (2015).

6. For further information, refer to the outcome document of the Fourth High Level Forum on Aid Effectiveness, in Busan, Republic of Korea, 29 Nov. to 1 Dec. 2011: https://www.oecd.org/dac/effectiveness/49650173.pdf.

7. For further information, refer to the outcome document of the first HLM of the GPEDC, in Mexico, 15-16 Apr. 2014: https://effectivecooperation.org/ wp-content/uploads/2015/01/MEMORIA-FINAL.pdf, and the outcome document of the second HLM of the GPEDC, in Kenia, Nairobi, I Dec. 2016: http://effectivecooperation.org/wp-content/uploads/2016/12/ OutcomeDocumentEnglish.pdf.

8. For further information please refer to: https://www.un.org/ecosoc/en/tra cking-development-cooperation.

9. However, the fact that the members of the steering committee set the standards for accountability - but are at the same time part of the stakeholders held accountable - may threaten the GPEDC's credibility.

10. For more information, refer to: https://www.un.org/esa/ffd/ffdforum/.

11. Note that we refer to the targets of the SDGs, as they constitute about the same level as the GPEDC indicators. We do not consider the targets related to international commitments with respect to ODA funds, as it is not in the current mandate of the GPEDC to monitor whether the development partner countries comply with these commitments, as discussed in the previous section. 
12. These targets refer to gender equality and women's empowerment (Target 5.C), public access to information, policy coherence (Target 17.14), the respect for each country's policy space and leadership (Target 17.15), enhancing the global partnership (Target 17.16), public-private and civil society partnerships (Target 17.17), and statistical capacity-building (Target 17.19).

13. These targets refer to the mobilisation of financial resources from a variety of sources (Targets 1.A and 17.3), pro-poor and gender sensitivity of national development frameworks (Target 1.B), quality of national procurement systems (Target 12.7), quality of institutions (Target 16.6), in particular the rule of law (16.3) and control of corruption (16.5), the participation of development countries in the institutions of global governance (Target 16.8), and knowledge cooperation in the form of North-South, SSC, and triangular cooperation (Target 17.6).

14. For further information refer to: https://www.cgdev.org/page/quality-odaquoda and https://www.cgdev.org/commitment-development-index-2018.

15. The dashboard can be accessed here: http://dashboard.effectivecooperation. org/viewer.

16. The global report as well as the country briefs for the most recent monitoring round can be accessed here: http://effectivecooperation.org/monitoring-cou ntry-progress/country-and-territory-monitoring-profiles/.

17. The deployment of blended finance remains quite limited in the relatively lessdeveloped countries (see e.g. Bhattacharya and Khan 2018a).

18. Up to date, only in three countries (Dominican Republic, Egypt, and Lao PDR), the 2016 monitoring results have been used for the preparation of VNRs.

\section{REFERENCES}

Abdel-Malek, T. (2015). The Global Partnership for Effective Development Cooperation: Origins, actions and future prospects (DIE Studies 88). Bonn: German Development Institute/Deutsches Institut für Entwicklungspolitik (DIE).

Attridge, S., \& Engen, L. (2019, April). Blended finance in the poorest countries: The need for a better approach. London: Overseas Development Institute.

Barder, O. (2018). Aid in the national interest: When is development cooperation winwin? https://www.cgdev.org/blog/aid-national-interest-when-development-cooper ation-win-win.

Besharati, N. (2013). A year after Busan: Where is the Global Partnership going? (Occasional Paper 136). Johannesburg: South African Institute of International Affairs.

Besharati, N., Rawhani, C., \& Rios, O. G. (2017, March). A monitoring and evaluation framework for South-South cooperation (NEST Working Paper). Johannesburg: South African Institute of International Affairs.

Bexell, M., \& Jönsson, K. (2017). Responsibility and the United Nations' Sustainable Development Goals. Forum for Development Studies, 44(1), 13-29.

Bhattacharya, D., \& Khan, S. (2018a). Is blended finance trending in the LDCs? Perspectives from the ground (Occasional Paper Series 49). (n.p.). Southern Voice.

Bhattacharya, D., \& Khan, S. (2018b). Why do we need to rethink development effectiveness? http://southernvoice.org/why-do-we-need-to-rethink-development-effect iveness/. 
Bhattacharya, D., \& Rashmin, R. (2016). Concessional financial flows among Southern countries: Conceptualising design principles, operational modalities and an assessment framework. New York, NY: United Nations Development Programme.

Bhattacharya, D., Rashmin, R., \& Mahfuze, A. H. (2016). Strengthening accountability in development cooperation role of GPEDC monitoring indicators in the context of Agenda 2030 and AAAA (Occasional Paper Series 29). (n.p.). Southern Voice.

Booth, D. (2012). Development as a collective action problem: Addressing the real challenges of African governance: Synthesis report of the Africa Power and Politics Programme (Synthesis Report). London: Africa Power and Politics Programme.

Bowen, K. J., Cradock-Henry, N. A., Koch, F., Patterson, J., Häyhä, T., Vogt, J., et al. (2017). Implementing the "Sustainable Development Goals": Towards addressing three key governance challenges - collective action, trade-offs, and accountability. Current Opinion in Environmental Sustainability, 26-27, 90-96.

Constantine, J., Shankland, A., \& Gu, J. (2015). Engaging the rising powers in the Global Partnership for Effective Development Cooperation: A framing paper. https://effectivecooperation.org/wp-content/uploads/2016/08/GPEDCEngagement-with-BRICS_IDS-Framing-Paper_New_June2015.pdf.

Coppard, D., \& Culey, C. (2015). The Global Partnership for Effective Development Co-operation's contribution to the 2030 Agenda for Sustainable Development. http://devinit.org/wp-content/uploads/2015/12/Contribution-tothe-2030-Agenda-for-Sustainable-Development_FULL.pdf.

Engberg-Pedersen, P., \& Zwart, R. (2018). The 2030 Agenda and development cooperation results (Development Policy Papers 9). Paris: Organisation for Economic Co-operation and Development.

Fukuda-Parr, S. (2017). Millennium development goals: Ideas, interests and influence. Abingdon: Routledge.

Fukuda-Parr, S., \& McNeill, D. (2019). Knowledge and politics in setting and measuring SDGs. Global Policy, 10(S1), 5-15.

GPEDC/UNDP (Global Partnership for Effective Development Cooperation/United Nations Development Programme). (2016). Making development cooperation more effective: 2016 progress report. Paris: Organisation for Economic Co-operation and Development.

GPEDC. (2017). 2017 and 2018 programme of work. https://effectivecooperation. org/wp-content/uploads/2017/05/2017-18-Global-Partnership-Work-Progra mme.pdf.

GPEDC. (2018). 2018 monitoring round. Mini guide for development partners. http://effectivecooperation.org/pdf/2018MiniGuide_DevPartners.pdf.

GPEDC. (2019a). 3rd Global Partnership monitoring round: Update on process and preliminary findings. https://effectivecooperation.org/wp-content/uploads/ 2019/03/Monitoring-Update-Session-2.pdf.

GPEDC. (2019b). South-South cooperation effectiveness. https://effectivecooperation. org/wp-content/uploads/2019/03/Monitoring-SSC-Session-3.pdf.

Hulme, D. (2016). Should rich nations help the poor? Cambridge: Polity Press.

Keijzer, N., Klingebiel, S., Örnemark, C., \& Scholtes, F. (2018). Seeking balanced ownership in changing development cooperation relationships (EBA Rapport 2018:08). Stockholm: Expert Group for Aid Studies.

Kharas, H., \& Rogerson, A. (2017, October). Global development trends and challenges: Horizon 2025 revisited. London: Overseas Development Institute. 
Kim, E. M. (2013). Busan and beyond: South Korea and the transition from aid effectiveness to development effectiveness. Journal of International Development, 25(6), 787-801.

Knack, S. (2012). When do donors trust recipient country systems? (Policy Research Working Paper 6019). Washington, DC: World Bank.

Koch, S., Leiderer, S., Faust, J., \& Molenaers, N. (2017). The rise and demise of European budget support: Political economy of collective European Union donor action. Development Policy Review, 35(4), 455-473.

Leiderer, S. (2015). Donor coordination for effective government policies? Journal of International Development, 27(8), 1422-1445.

Li, X. (2017). Should China join the GPEDC? The prospects for China and the Global Partnership for Effective Development Co-operation (DIE Discussion Paper 17/2017). Bonn: German Development Institute/Deutsches Institut für Entwicklungspolitik (DIE).

Lundsgaarde, E., \& Keijzer, N. (2016, July). Sustaining the development effectiveness agenda (Policy Brief). Copenhagen: Danish Institute for International Studies.

Mahn, T. (2017). Accountability for development cooperation under the 2030 Agenda (DIE Discussion Paper 10/2017). Bonn: German Development Institute/Deutsches Institut für Entwicklungspolitik (DIE).

Mawdsley, E., Murray, W. E., Overton, J., Scheyvens, R., \& Banks, G. (2018). Exporting stimulus and "shared prosperity": Reinventing foreign aid for a retroliberal era. Development Policy Review, 2018(36), O25-O43.

Monitoring Advisory Group. (2016). Report to the tenth steering committee meeting, New York, July 14-15, 2016. https://effectivecooperation.org/wp-content/upl oads /2016/07/Final-July-6th-Monitoring-Advisory-Group-Report-for-SC.pdf.

OECD (Organisation for Economic Co-operation and Development). (2018a). Making blended finance work for the Sustainable Development Goals. Paris: Organisation for Economic Co-operation and Development.

OECD. (2018b). Perspectives on global development 2019. Paris: Organisation for Economic Co-operation and Development.

The World in 2050. (2018). Transformations to achieve the Sustainable Development Goals. Laxenburg: International Institute for Applied Systems Analysis.

UN (United Nations). (2015). Resolution adopted by the General Assembly on 25 September 2015. http://www.un.org/ga/search/view_doc.asp?symbol=A/RES/ $70 / 1 \&$ Lang=E.

UN. (2018). The Sustainable Development Report 2018. New York, NY: United Nations.

United Nations Economic and Social Council. (2018). National mutual accountability and transparency in development cooperation: Study on the findings of the fifth DCF Survey 2018. New York, NY: United Nations.

Wehrmann, D. (2018). Multi-actor partnerships and private-sector engagement in development cooperation incentivising and regulating strategies (DIE Discussion Paper 21/2018). Bonn: German Development Institute/Deutsches Institut für Entwicklungspolitik (DIE).

Wood, B., Betts, J., Etta, F., Gayfer, J., Kabell, D., Ngwira, N., \& Samaranayake, M. (2011). The evaluation of the Paris Declaration: Final report. Copenhagen: Danish Institute for International Studies.

World Bank. (2003). World Development Report 2004: Making services work for poor people. Washington, DC: World Bank. 
Open Access This chapter is licensed under the terms of the Creative Commons Attribution 4.0 International License (http://creativecommons.org/licenses/by/4.0/), which permits use, sharing, adaptation, distribution and reproduction in any medium or format, as long as you give appropriate credit to the original author(s) and the source, provide a link to the Creative Commons license and indicate if changes were made.

The images or other third party material in this chapter are included in the chapter's Creative Commons license, unless indicated otherwise in a credit line to the material. If material is not included in the chapter's Creative Commons license and your intended use is not permitted by statutory regulation or exceeds the permitted use, you will need to obtain permission directly from the copyright holder. 